\title{
Surgical outcomes of 14 consecutive bilateral cleft lip patients treated with a modified version of the Millard and Manchester methods
}

\author{
Mustafa Zahi Al-Zajrawee ${ }^{1}$, Mohammed Abd-Alhussein Aljodah'2, Qays Ahmed Hassan ${ }^{2}$ \\ ${ }^{1}$ Department of Surgery, University of Kufa College of Medicine, Najaf; ${ }^{2}$ Department of Surgery, University of Baghdad Al-Kindy College of \\ Medicine, Baghdad, Iraq
}

Background Bilateral cleft lip deformity is much more difficult to correct than unilateral cleft lip deformity. The complexity of the deformity and the sensitive relationships between the arrangement of the muscles and the characteristics of the external lip necessitate a comprehensive preoperative plan for management. The purpose of this study was to evaluate the repair of bilateral cleft lip using the Byrd modification of the traditional Millard and Manchester methods. A key component of this repair technique is focused on reconstruction of the central tubercle.

Methods Fourteen patients with mean age of 5.7 months presented with bilateral cleft lip deformity and were operated on using a modification of the Millard and Manchester techniques. Patients with a very wide cleft lip and protruded or rotated premaxilla were excluded from this study. We analyzed 30 normal children for a comparison with our patients in terms of anthropometric measurements.

Results By the end of the follow-up period (between 9 and 19 months), all our patients had obtained a full central segment with adequate white roll in the central segment and a deep gingivolabial sulcus, and we obtained nearly normal anthropometric measurements in comparison with age-matched normal children.

Conclusions We recommend this modified technique for the treatment of bilateral cleft lip deformity.

Keywords Cleft lip / Patient outcome assessments / Byrd / Repair technique
Correspondence: Qays Ahmed Hassan Department of Surgery, University of Baghdad Al-Kindy College of Medicine, Al-Nahdha Square, Baghdad 10071, Iraq Tel: +964-1-776-30-91 Fax: +964-1-776-35-92 E-mail: qtimeme@yahoo.com

Received: 20 Mar $2018 \bullet$ Revised: 21 Dec $2018 \bullet$ Accepted: 21 Dec 2018

pISSN: 2234-6163 • elSSN: 2234-6171 • https://doi.org/10.5999/aps.2018.00332 • Arch Plast Surg 2019;46:114-121

\section{INTRODUCTION}

Bilateral cleft lip accounts for $15 \%$ of all cases of cleft lip anomaly [1], and it is much more difficult to correct than unilateral cleft lip $[2,3]$. Some authors have even affirmed that bilateral cleft deformity is twice as challenging to repair as unilateral cleft lip, and the effects are just half as good [4]. Surgical correction of bilateral cleft deformity has always focused on closure of both sides of the lip. Staged repair of one side and closure of the other side has been superseded by simultaneous, symmetrical closure of both sides [5-8].

In the history of the development of bilateral cleft lip repair, a number of surgical procedures with many variations have been described, including the techniques of Veau, Tennison, Man- 
chester, Millard, and others [9]. The Veau III procedure is a straight-line closure without elevation of the prolabial skin, and therefore, without any effort to reconstruct the continuity of the orbicularis oris. Zigzag procedures, such as those of Tennison which are useful in unilateral cleft lip deformities, were also adapted for the repair of bilateral cleft lip [10]. Manchester preferred to maintain the prolabial vermilion to create the cupid's bow and tubercle, but similarly to Veau, Manchester's technique did not involve repairing the orbicularis, as he felt that doing so would create an overly tight lip [9]. Unlike Manchester, Millard's technique included total elevation of the prolabium and reconstitution of the orbicularis across the premaxilla, with the central vermilion recreated from the lateral lip portions [11].

Thus, throughout the history of bilateral cleft lip repair, the central vermilion has been reconstructed by two general methods. One of these techniques uses lateral lip elements that are brought together underneath the prolabium, thereby producing a tight lip inferiorly that may be unnatural-looking. An alternative method for central vermilion creation is turndown of the buccal mucosa attached to the bottom of prolabial skin, followed by wrapping it under the repair and connecting the lateral lip elements; however, this technique can lead to central vermilion notch $[2,3]$.

In this study we aimed to evaluate the surgical outcomes of a modification of the two aforementioned methods (the Millard and Manchester techniques) for bilateral cleft lip repair; this technique was developed by Byrd on the basis of over 25 years of surgical experience dealing with bilateral cleft lip [12].

\section{METHODS}

\section{Patients}

A total of 14 patients ( 8 males and 6 females) presented for correction of bilateral cleft lip. Their ages ranged from 3 to 10 months, with a mean age of 5.7 months. We excluded patients who had a very wide cleft lip and those with a severely protruded or rotated premaxilla. All operations were performed between January 2013 and April 2016. Ten of our patients had a positive family history of bilateral or unilateral cleft lip, and nine had a cleft palate in association with bilateral cleft lip. None of our patients had any other associated congenital anomalies. At the time of presentation, we instructed our patients to use rubber band traction over the premaxilla and palatal acrylic plate in order to facilitate the repair and to prevent lateral maxillary collapse.

\section{Ethical issues}

Ethical clearance for the study was obtained from the local insti- tutional Scientific and Ethics Committee (approval number $32 / 2012$ ) before commencement of the study. Informed consent was obtained from each patient's parents for the publication of any accompanying photographs. Some preoperative, intraoperative, and postoperative clinical photographs were also obtained and are shown with permission.

\section{Preoperative measurements}

A general evaluation of the medical status of all patients was performed, with an assessment of any associated congenital anomalies. All patients' weight was measured. Routine preoperative investigations were done, including hemoglobin levels, prothrombin time, partial thromboplastin time, and a virology screening. Frontal and lateral photographs were taken of all patients.

\section{Anthropometric measurements}

The patients were divided by age, and measurements were taken of every patient both intraoperatively and at 1 year postoperatively. The labial anthropometric measurements included the following: upper lip height (subnasale-stomion; sn-sto), cutaneous upper lip height (subnasale-labial superioris; sn-ls), and vermilion mucosal height (labial superioris-stomion; ls-sto). These measurements were also made in a control group of 30 normal children to compare our preoperative and postoperative results.

\section{Surgical repair procedures}

All operations were undertaken under general anesthesia. The patients were placed in the supine position, and the face was prepared and draped. Methylene blue was used to make the following markings (Fig. 1):

Point 1 was marked at the midline of the prolabium at mucocutaneous junction on the white roll. Points 2 and 3 represented the cupid's bow peaks, with the same width as the columellar base (approximately 5-6 mm). Points 2 ' and 3' represented the columellar base. The line connecting points 2 and $2^{\prime}$ and points 3 and 3' represented the future constructed philtral column (generally $8-12 \mathrm{~mm}$ in length). A curvilinear oblique line was designed from point 2 to 3 at the midline of the red line, so that a U-shaped flap was designed on the dry vermilion of the prolabium, with its tip at the wet-dry junction along the midline. Points 4 and 5 were marked on the white roll at the location of the maximal fullness of the dry vermilion (lateral lip segment); both points 4 and 5 would meet points 2 and 3, corresponding to the cupid's bow peak. Points 8 and 9 represented the alar base. The vertical length of the lateral segment extended up from points 4 and 5 toward the alar base. To maintain uniform length across the upper lip, the newer alar base was marked with points $8^{\prime}$ and $9^{\prime}$ if the lateral segment was longer than the prola- 


\section{Fig. 1. Schematic drawings of bilateral cleft lip repair}

(A) Point 1 was marked at the midpoint of the prolabial cupid's bow. Point's 2 ' to $3^{\prime}$ represent the columellar base width. A U-flap was marked by a curvilinear oblique line from points 2 and 3 in the midline of the red dry vermilion of the prolabium, with its tip at the wet-dry junction along the midline. Points 4 and 5 were marked on the white roll at the location of the maximal fullness of the dry vermilion (lateral lip segment). Points 8 and 9 represent the alar base. Newer alar base was marked with points $8^{\prime}$ and $9^{\prime}$ if the lateral segment was longer than the prolabial height, so that the excess skin between points 8 and $8^{\prime}$ and 9 and $9^{\prime}$ would be excised. The vertical length of the lateral segment extended up from points 4 and 5 toward the alar base. Points 6 and 7 were marked along the dry vermilion where it faded into the cleft (lateral lip segment), where it met points ${ }^{\prime}$ and $3^{\prime}$ during the repair. The lines between points 4 and 6 and points 5 and 7 corresponded to future philtral columns. (B) Marking of incisions of the Ushaped flap and both of $L$ and $M$ flaps.
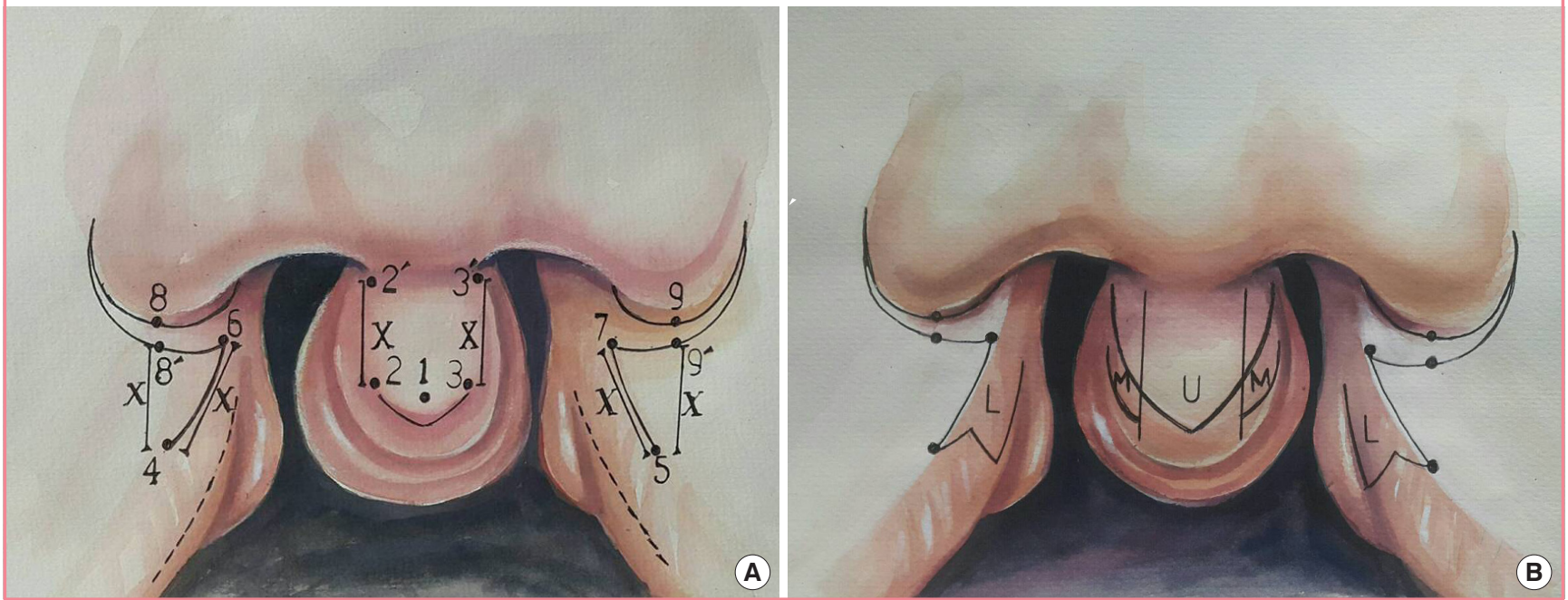

bial height, so that the excess skin between points 8 and $8^{\prime}$ and 9 and $9^{\prime}$ would be excised. Points 6 and 7 were marked along the dry vermilion where it faded into the cleft (lateral lip segment), and were designed so that they would meet points 2 ' and 3 ' during the repair. The line between points 4 and 6 and points 5 and 7 corresponded to the future philtral columns.

The central tubercle was reconstructed from lateral flaps, following the guideline that the length of the vermilion advancement flap should be slightly greater than one-half of the prolabial width.

\section{Operative technique}

The lip was infiltrated with local anesthetic (2\% xylocaine with 1/200,000 adrenaline). An incision was made with a No. 15 scalpel, beginning first at the prolabium, and then a U-shaped flap was elevated with maintenance of good thickness of the flap in order to maintain a satisfactory blood supply. The U-shaped prolabial flap was elevated up to the columellar base, a vertical midline incision was made on its deep surface, and this incision was deepened until the dermis was exposed, thereby creating the future philtral dimple where it was sutured to the underlying muscle. Bilateral columellar fork flaps were elevated from both sides of the prolabial flap; these flaps were discarded and not used in our repair, except at the base to facilitate closure of the nasal floor. After that, bilateral prolabial M-flaps were created by incising the lateral mucosal pairing of the prolabium on both sides; these flaps were used to line the alveolar and nasal floor. The central mucosal segment was dissected by scissors, advanced over the raw surface of the anterior premaxilla, and sutured to the base of the columella by 5/0 Vicryl, thereby providing the lining of the labial sulcus. After that, an incision was made at the lateral lip, and an L-flap was dissected and carefully elevated from the vermilion of the lateral segment, with its base on the alveolus, to be used for the lateral nasal lining. We incised the gingivobuccal sulcus to release the mucosal lining, and subperiosteal wide undermining was carried out up to the inferior orbital nerve. This wide dissection allowed the lateral lip segment to be advanced to the prolabium in a tension-free manner. The skin and mucosa were dissected away from the muscle fibers, with care taken not to elevate the mucosa from the deep muscle fibers at the vermilion. Any muscular attachment to the alar base was released and dissected away, after which a fullthickness cut was made along the nasal lining at the pyriform aperture. The resulting defect was filled by suturing the L-flap to the defect using 5/0 Vicryl. A 3-point alar cinch suture was placed to secure the muscle of the alar base to the premaxilla in the midline. Next, we sutured the M-flap to the medial base of the L-flap, also using 5/0 Vicryl, and the inferior border of the M-flap was sutured to the superior border of the lateral lip mucosal segments using the same sutures, after which we sutured 
the lateral lip mucosal segments together. We approximated the orbicularis muscle using a 3-point fixation suture to the midline of the premaxilla by bringing the superomedial margins of the muscle bilaterally to the columellar base and suturing using $4 / 0$ polydioxanone. Additional simple interrupted stitches were placed in the central muscle for additional support. The deep muscle fibers from the lateral lip segment were sutured to the midline using 4/0 Vicryl to form the tubercle, and the mucosa of the lateral lip segment was sutured to the midline using the same sutures. Finally, we sutured the dermis of the prolabium to the orbicularis muscle at the midline using $5 / 0$ Vicryl, and the skin of the lateral lip segments was approximated to the central prolabial flap using $6 / 0$ polypropylene. The lateral vermilion flaps were closed along the borders of the U-flap of the prolabial dry vermilion, thereby creating a full tubercle. The alar base vestibular skin was sutured to the base of the fork flap using 5/0 Vicryl. A Steri-Strip was used to cover the wound and then removed on the first postoperative day, at which point the wound was inspected, and a Steri-Strip was reapplied. The sutures were removed on the fifth postoperative day and Steri-Strips were continuously applied to the wound for at least 2 weeks postoperatively. The patients were followed up for 1 year postoperatively.

\section{Statistical analysis}

Statistical analyses were performed for the intraoperative and postoperative measurements. Continuous variables were expressed as mean \pm standard deviation. The paired t-test was used to analyze continuous variables. P-values less than 0.05 were

Table 1. Distribution of patients according to the extent of cleft lip on both sides

\begin{tabular}{|lc|}
\hline & No. of patients (\%) \\
\hline Bilateral complete & $5(35.72)$ \\
Bilateral incomplete & $5(35.72)$ \\
Bilateral asymmetrical & $4(28.57)$ \\
\hline
\end{tabular}

considered to indicate statistical significance. Statistical analyses were performed using SPSS for Windows version 19.0 (IBM Corp., Armonk, NY, USA).

\section{RESULTS}

The cases of bilateral cleft lip ranged from complete to incomplete and asymmetrical on both sides, as shown in Table 1.

For all anthropometric measurements, significant differences were observed between the intraoperative values and those obtained at 1 year of follow-up $(\mathrm{P}<0.05)$. A comparison between the patients and normal age-matched children showed significant differences for all anthropometric measurements intraoperatively and at 1 year of follow-up, except for sn-ls, which showed no significant difference $(\mathrm{P}=0.061)$, as shown in Table 2 .

Postoperative complications were observed in five patients, as shown in Table 3. Patients who developed whistle deformity and white roll malalignment were candidates for subsequent secondary lip revision. One patient who developed postoperative partial wound dehiscence was managed conservatively with the application of topical antibiotics, and the wound healed. In patients who developed a hypertrophic scar, anti-scar therapy was applied for up to 6 months, and the healing of the scar was acceptable at 6 months postoperatively.

The overall results were satisfactory over the course of a follow-up period that ranged from 9 to 19 months, and we obtained a full central segment with a prominent philtral ridge, adequate white roll in the central segment, and a thick vermilion with a seam-like median tubercle. This method also provided a

Table 3. Postoperative complications in chronological sequence

\begin{tabular}{|lc|}
\hline Postoperative complications & No. of patients (\%) \\
\hline Wound dehiscence & $1(7.14)$ \\
Hypertrophic scar & $2(14.28)$ \\
White roll malalignment & $1(7.14)$ \\
Whistle deformity & $1(7.14)$ \\
\hline
\end{tabular}

Table 2. Labial anthropometric measurements of patients with bilateral cleft lip compared with age-matched averages of children without cleft lip

\begin{tabular}{|c|c|c|c|c|c|c|}
\hline Anthropometric measurements & $\begin{array}{l}\text { Intraoperative } \\
\text { measurements } \\
(\mathrm{mm})\end{array}$ & $\begin{array}{l}\text { Normal age- } \\
\text { matched averages } \\
(\mathrm{mm})\end{array}$ & P-value & $\begin{array}{c}\text { After approximately } \\
1 \text { year of follow-up } \\
\text { (mm) }\end{array}$ & $\begin{array}{l}\text { Normal age- } \\
\text { matched averages } \\
(\mathrm{mm})\end{array}$ & P-value \\
\hline Upper lip height (sn-sto) & $7.6 \pm 1.1$ & $14.0 \pm 1.2$ & $<0.001$ & $15 \pm 2.2$ & $17.0 \pm 2.5$ & 0.005 \\
\hline Cutaneous lip height (sn-Is) & $5.0 \pm 0.7$ & $9.8 \pm 0.9$ & $<0.001$ & $10.0 \pm 1.9$ & $11.0 \pm 1.7$ & 0.061 \\
\hline Vermilion mucosal height (Is-sto) & $2.5 \pm 0.4$ & $4.0 \pm 0.5$ & $<0.001$ & $4.5 \pm 0.8$ & $6.0 \pm 1.1$ & $<0.001$ \\
\hline
\end{tabular}


Fig. 2. Case example no. 1

A 3-month-old male patient with asymmetrical bilateral cleft lip. (A) Preoperative frontal view. (B) Immediate postoperative image. (C) Postoperative results at 15 months. (D) Postoperative lateral view at 15 months.
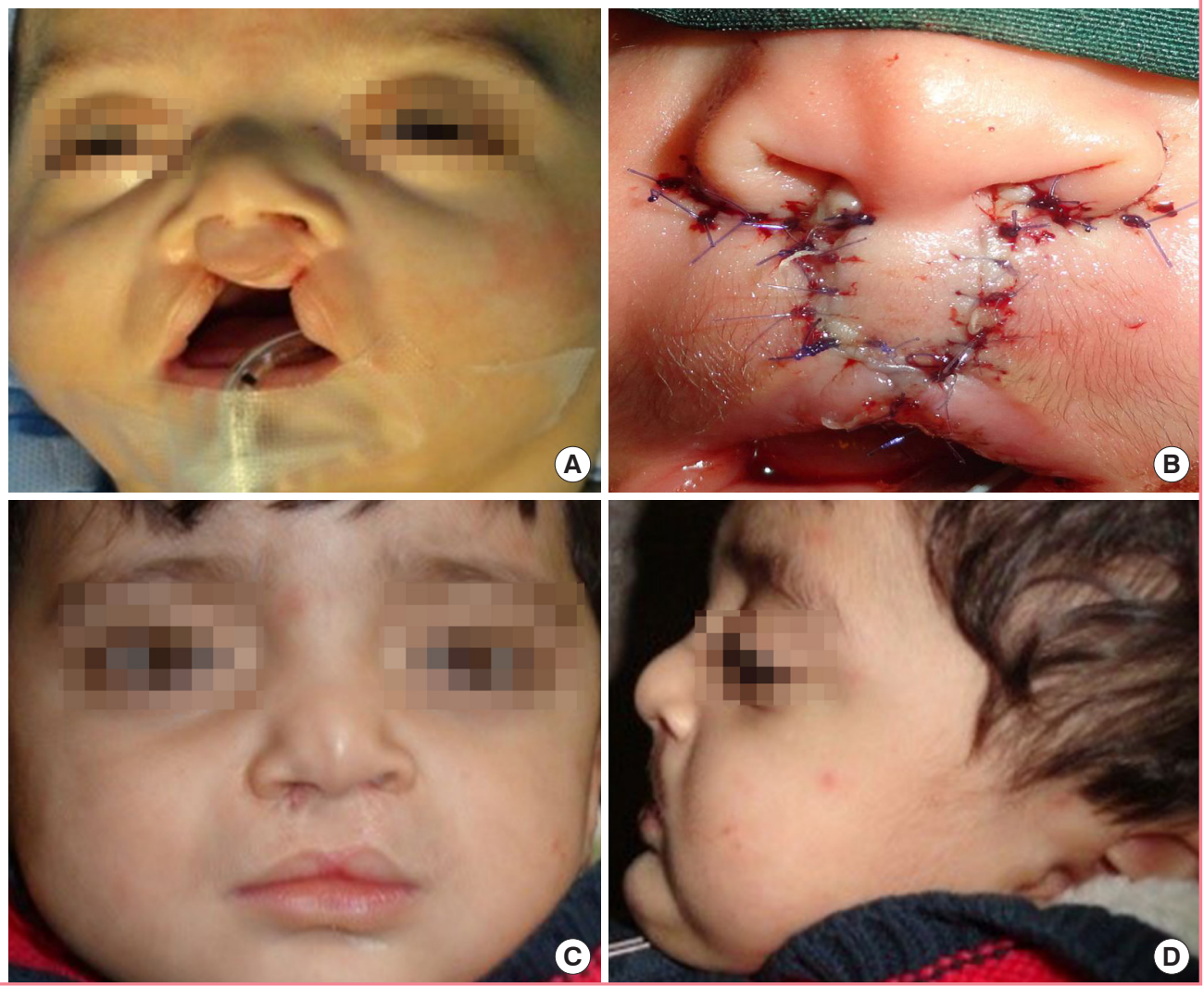

Fig. 3. Case example no. 2

Byrd surgical technique in a 4month-old female patient with bilateral incomplete cleft lip. (A) Preoperative frontal image. (B) Immediate postoperative image. (C) Ninemonth postoperative frontal image. (D) Adequate labiogingival sulcus is seen.
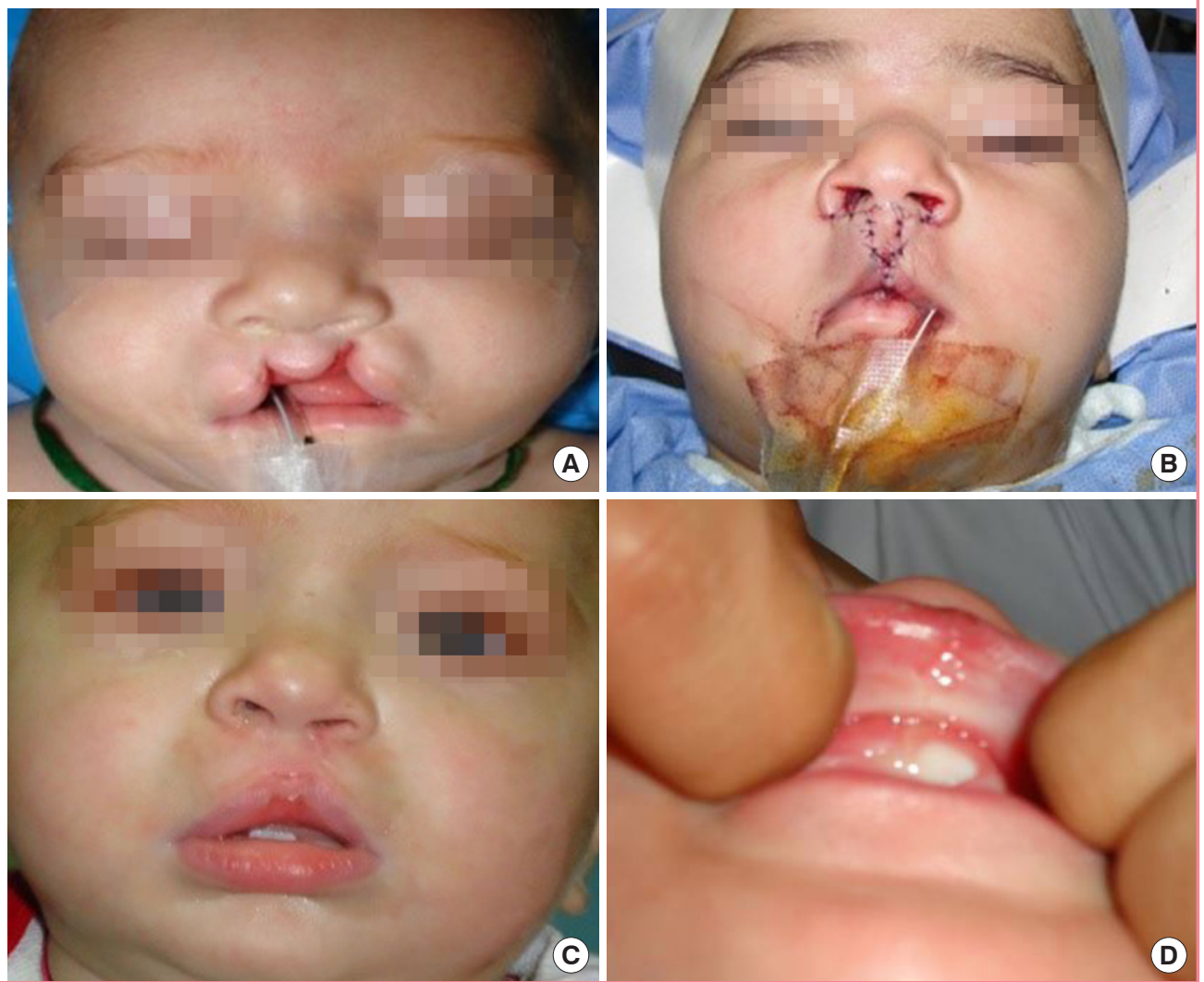


\section{Fig. 4. Case example no. 3}

A 4-month-old male with bilateral complete cleft lip had Byrd surgical repair. (A) Preoperative frontal image. (B) Immediate postoperative image. (C) The results at postoperative 6 months.
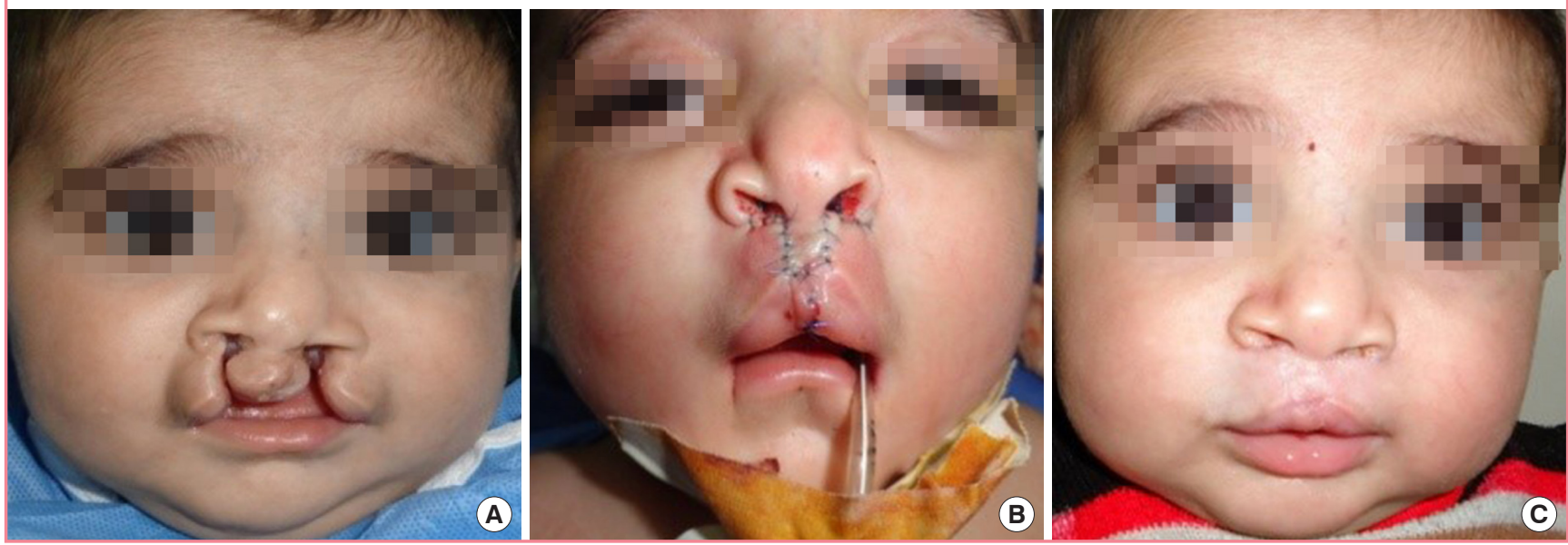

deep gingivolabial sulcus. Furthermore, at the end of the 1-year follow-up, we obtained nearly normal anthropometric measurements in comparison with the age-matched controls.

Preoperative and postoperative images of three patients are shown in Figs. 2-4.

\section{DISCUSSION}

The outcomes of bilateral cleft repairs have historically been disappointing because of resulting deformities or newly created functional problems. The deformities encountered include a wide philtrum, a tight upper lip, a broad and flattened nose, a widened scar, and whistle deformity [13-15]. The surgeon is faced with the challenge of creating an aesthetically pleasing and normally functioning lip using a prolabium that is often significantly protruded and that is deficient of orbicularis oris muscle. Over the years, a myriad of surgical repair techniques has been used and abandoned an attempt to achieve good aesthetic and functional results [16].

There are two general methods for constructing the central lip vermilion. One involves using mucosa visible in the inferior aspect of the prolabial skin to form the central vermilion, as is done in Manchester's repair. The advantage of using the prolabial or buccal mucosa to create the vermilion is that very little bulk from the lateral segments of the vermilion is required, thereby decreasing the tension required for the closure across the cleft. The disadvantages of this technique are (1) that there are two parallel scars across the vermilion; (2) that the central buccal mucosa does not possess the same minor salivary gland distribution as the lateral vermilion tissue, often resulting in a dry, chapped central vermilion segment [7]; and (3) the inadequate tubercle and the central depression of the upper lip vermilion [12].

A second approach is to use the vermilion tissue from lateral lip segments to create the central vermilion as a variation of the technique described by Millard. The muscle of the lateral lip element rotates down with full-thickness vermilion flaps and can be used to create a satisfactory central vermilion with a single vertical scar under the depth of the cupid's bow [7]. The disadvantage of this method is that it results in a tight upper lip $[9,16]$.

In our study, bilateral cleft lips were repaired using the Byrd modification of the traditional Millard and Manchester methods [12]. These modifications are as follows: constructing a Ushaped flap from the dry vermilion of the prolabium to reconstruct the tubercle, primary sulcoplasty, using a 3-point fixation suture in orbicularis oris muscle repair, and when the lateral lip segment is slightly long relative to the prolabial height, resection of a small crescent-shaped edge of skin from the alar base to decrease the height.

Common problems faced in bilateral cleft lip repair include scars across the white roll of the central segment, a broad and unattractive prolabium, unequal lip segments, a shallow sulcus, an empty central segment, a short central segment, and a tight lip [13-15]. All these problems are addressed in our method.

By making a U-shaped incision through the dry vermilion of the prolabium, the resulting scar drops into the mucosal lip, rather than the white roll, resulting in a more favorable aesthetic appearance.

When the lateral lip muscle is sutured to the lateral segment of the prolabium, or where it is inadequately sutured in the midline, progressive contraction of the muscle with growth usually leads to an overly wide interphiltral distance. However, this problem was addressed in our modification by approximating 
the midline of orbicularis muscle to the midline of the premaxilla using a 3-point fixation suture. This 3-point fixation suture brings the superomedial margin of the muscle bilaterally to the columellar base. Additional simple sutures are placed in the central muscle for additional support, and repairing the muscle in the midline results in a more dynamic lip and normal appearance of the prolabium.

In addition, the underside of the philtral flap is stored vertically in the midline, and the central dermis was sutured to the area where the underlying muscle was repaired to create a central philtral dimple.

For a balanced upper lip, we resected a wedge of less than 3 $\mathrm{mm}$ of excess lateral lip superiorly. This maneuver equilibrates the lateral lip segments to the prolabial height.

Primary prolabial sulcoplasty was done in our method. The congenital shallowness of the prolabial labio-gingival sulcus receives little attention during primary repair of bilateral cleft lip and is usually recognized as a secondary problem [17]. We found that primary sulcoplasty showed good results in term of allowing free movement of the upper lip without restriction. Another advantage of primary sulcoplasty in our study was a decreased incidence of whistle deformity.

There is enough lateral marginal muscle in the vermilion flap to adequately fill and reconstruct the tubercle by transferring only dry and wet vermilion, without skin or white roll, thereby avoiding a scar along the philtral inset and a tight upper lip, as seen in the Millard technique. The inset of this dry vermilion flap was designed to fit beneath the native dry vermilion of the prolabial segment, thereby avoiding the central tubercle deficiency and whistle deformity that occur in Manchester repair [12].

Our final results showed a smooth, symmetrical, well-aligned cupid's bow, without any scar traversing its white roll, with good central tubercle bulk that yielded a favorable aesthetic appearance, both according to the parents of the child and another plastic surgeon.

In our study, three anthropometric measurements were made: upper lip height (sn-sto), cutaneous lip height (sn-ls), and vermilion mucosal height (ls-sto). The growth of the upper lip was analyzed by comparing the patients' anthropometric measurements to age-matched normal children preoperatively and at 1 year postoperatively. Upper lip height (sn-sto) was $88 \%$ of normal, cutaneous lip height (sn-ls) was $90 \%$ of normal, and vermilion mucosal height (ls-sto) was $75 \%$ of normal. These measurements approached normal values after 1 year of follow-up, which is inconsistent with the results of Kim et al. [18], who reported values of $88 \%, 80 \%$, and $93 \%$ of normal for upper lip height (sn-sto), cutaneous lip height (sn-ls), and vermilion mucosal height (ls-sto), respectively, at 1 year of postoperative fol- low-up. However, the follow-up period in that study was longer than in ours, and at 5 years of postoperative follow-up, the anthropometric measurements of the patients in that study showed results that were very close to normal in comparison with age-matched averages.

In conclusion, using a U-shaped prolabial dry vermilion flap that was augmented by lateral lip vermilion flaps (without skin or white roll) could improve central vermilion fullness without sacrificing the lateral lip segment and while avoiding a tight upper lip. We recommend this procedure for the treatment of bilateral cleft lip, but suggest that the follow-up period should be extended for at least 5 years postoperatively.

There were a few limitations of this study. First, we did not attempt to reconstruct the white roll (if it was absent), in order to avoid a cutaneous scar that would result in a thick-appearing white roll. Second, the follow-up period was limited, ranging from 9 to 19 months, whereas an ideal follow-up period would extend to adulthood.

\section{NOTES}

\section{Conflict of interest}

No potential conflict of interest relevant to this article was reported.

\section{Ethical approval}

The study was approved by the Institutional Review Board of Medical City Hospital (IRB No. 32/2012) and performed in accordance with the principles of the Declaration of Helsinki. Written informed consents were obtained.

\section{Patient consent}

The patient's parents provided written informed consent for the publication and the use of their images.

\section{Author contribution}

Conceptualization: Al-Zajrawee MZ, Aljodah MA. Data curation: Al-Zajrawee MZ, Hassan QA. Formal analysis: Aljodah MA, Hassan QA. Methodology: Al-Zajrawee MZ, Aljodah MA. Project administration: Al-Zajrawee MZ. Visualization: Aljodah MA, Hassan QA. Writing - original draft: Al-Zajrawee MZ, Hassan QA. Writing - review \& editing: Aljodah MA, Hassan QA.

\section{ORCID}

Mustafa Zahi Al-Zajrawee https://orcid.org/0000-0002-95006936

Mohammed Abd-Alhussein Aljodah https://orcid.org/00000002-1060-3206 
Qays Ahmed Hassan https://orcid.org/0000-0003-41121688

\section{REFERENCES}

1. Giele H, Cassele O. Plastic and reconstructive surgery (Oxford specialist handbook in surgery). New York: Oxford University Press; 2008.

2. Olasoji HO, Ukiri OE, Yahaya A. Incidence and aetiology of oral clefts: a review. Afr J Med Med Sci 2005;34:1-7.

3. Gorlin RJ, Cohen MM, Hennekam RC. Syndromes of the head and neck. New York: Oxford University Press; 2003.

4. Mulliken JB. Primary repair of bilateral cleft lip and nasal deformity. Plast Reconstr Surg 2001;108:181-94.

5. Spritz RA. The genetics and epigenetics of orofacial clefts. Curr Opin Pediatr 2001;13:556-60.

6. Vieira AR, Orioli IM. Candidate genes for nonsyndromic cleft lip and palate. ASDC J Dent Child 2001;68:272-9.

7. Hopper RA, Cutting C, Grayson B. Cleft lip and palate. In: Thorne CH, Bartlett SP, Beasley RW, et al., editors. Grabb and Smith's plastic surgery. 6th ed. Philadelphia: Lippincott Williams \& Wilkins; 2007. p. 201-25.

8. Yuzuriha S, Oh AK, Mulliken JB. Asymmetrical bilateral cleft lip: complete or incomplete and contralateral lesser defect (minor-form, microform, or mini-microform). Plast Reconstr Surg 2008;122:1494-504.

9. El-Hadidy AM, Eldeen AM, Elbassiony LE. An improved technique for repair of bilateral cleft lip deformities through extensive muscle dissection in one stage sugery Egypt. J Plast Reconstr Surg 2006;30:131-7.

10. Mulliken JB. Repair of bilateral cleft lip and its variants. Indian J Plast Surg 2009;42 Suppl:S79-90.

11. Millard DR Jr. Closure of bilateral cleft lip and elongation of columella by two operations in infancy. Plast Reconstr Surg 1971;47:324-31.

12. Byrd HS, Ha RY, Khosla RK, et al. Bilateral cleft lip and nasal repair. Plast Reconstr Surg 2008;122:1181-90.

13. Mulliken JB, Burvin R, Farkas LG. Repair of bilateral complete cleft lip: intraoperative nasolabial anthropometry. Plast Reconstr Surg 2001;107:307-14.

14. Gundlach KK, Schmitz R, Maerker R, et al. Late results following different methods of cleft lip repair. Cleft Palate J 1982;19:167-71.

15. Fillies T, Homann C, Meyer U, et al. Perioperative complications in infant cleft repair. Head Face Med 2007;3:9.

16. Mulliken JB, Wu JK, Padwa BL. Repair of bilateral cleft lip: review, revisions, and reflections. J Craniofac Surg 2003;14: 609-20.

17. Jackson IT, Fasching MC. Secondary deformities in cleft lip and palate. In: McCarthy JG, editor. Plastic surgery. 2nd ed. Philadelphia: Saunders; 1990. p. 2796.

18. Kim SK, Lee JH, Lee KC, et al. Mulliken method of bilateral cleft lip repair: anthropometric evaluation. Plast Reconstr Surg 2005;116:1243-51. 